OPEN ACCESS

Edited by:

Andy Pereira,

University of Arkansas, United States

Reviewed by:

Marian Brestic,

Slovak University of Agriculture,

Slovakia

Mathias Neumann Andersen,

Aarhus University, Denmark

Marcello Mastrorilli,

Consiglio per la Ricerca in Agricoltura

e l'Analisi dell'Economia

Agraria (CREA), Italy

*Correspondence:

Guangsheng Zhou

gszhou@camscma.cn

${ }^{+}$Co-first authors

Specialty section:

This article was submitted to

Plant Abiotic Stress,

a section of the journal

Frontiers in Plant Science

Received: 17 October 2017

Accepted: 04 April 2018

Published: 01 May 2018

Citation:

Ma X, He Q and Zhou G (2018, Sequence of Changes in Maize Responding to Soil Water Deficit and Related Critical Thresholds.

Front. Plant Sci. 9:511.

doi: 10.3389/fp/s.2018.00511

\section{Sequence of Changes in Maize Responding to Soil Water Deficit and Related Critical Thresholds}

\author{
Xueyan $\mathrm{Ma}^{1,2+}$, Qijin $\mathrm{He}^{3+}$ and Guangsheng Zhou ${ }^{1,4 *}$ \\ ${ }^{1}$ Chinese Academy of Meteorological Sciences, Beijing, China, ${ }^{2}$ Tianjin Meteorological Bureau, Tianjin, China, ${ }^{3}$ College of \\ Resources and Environmental Sciences, China Agricultural University, Beijing, China, ${ }^{4}$ Collaborative Innovation Center on \\ Forecast Meteorological Disaster Warning and Assessment, Nanjing University of Information Science \& Technology, \\ Nanjing, China
}

The sequence of changes in crop responding to soil water deficit and related critical thresholds are essential for better drought damage classification and drought monitoring indicators. This study was aimed to investigate the critical thresholds of maize growth and physiological characteristics responding to changing soil water and to reveal the sequence of changes in maize responding to soil water deficit both in seedling and jointing stages based on 2-year's maize field experiment responding to six initial soil water statuses conducted in 2013 and 2014. Normal distribution tolerance limits were newly adopted to identify critical thresholds of maize growth and physiological characteristics to a wide range of soil water status. The results showed that in both stages maize growth characteristics related to plant water status [stem moisture content $(\mathrm{SMC})$ and leaf moisture content (LMC)], leaf gas exchange [net photosynthetic rate $(\mathrm{Pn})$, transpiration rate (Tr), and stomatal conductance (Gs)], and leaf area were sensitive to soil water deficit, while biomass-related characteristics were less sensitive. Under the concurrent weather conditions and agronomic managements, the critical soil water thresholds in terms of relative soil moisture of 0-30 cm depth (RSM) of maize SMC, LMC, net Pn, $\mathrm{Tr}$, Gs, and leaf area were $72,65,62,60,58$, and 46\%, respectively, in seedling stage, and $64,64,51,53,48$, and $46 \%$, respectively, in jointing stage. It indicated that there is a sequence of changes in maize responding to soil water deficit, i.e., their response sequences as soil water deficit intensified: $S M C \geq L M C>$ leaf gas exchange $>$ leaf area in both stages. This sequence of changes in maize responding to soil water deficit and related critical thresholds may be better indicators of damage classification and drought monitoring.

Keywords: indicators, maize, sequence of changes, soil drought, soil moisture content, critical thresholds

\section{INTRODUCTION}

Crop growth is affected by a variety of abiotic factors, such as climate, cultivation, soil fertility, water efficiency, etc. (Meng et al., 2005; Guo et al., 2010; Alkaisi et al., 2015; Testa et al., 2016). Many of the impacts of climate and agronomical are felt by crops through the filter of soil moisture dynamics, because crops get their water from soil. Therefore, soil water deficit has the most significant impact on crops (Denmead and Shaw, 1962; Porporato et al., 2001). It restricts the 
growth, development, and yield of crops worldwide, consequently making losses exceeding the total caused by all other adverse factors (Ray et al., 2002; Neumann, 2008; Zivcak et al., 2008; Farooq et al., 2009; Bajgain et al., 2016; Petrov et al., 2017). Extensive studies on plant responses to soil water deficit at various levels (i.e., gene, cell, organ, individual) have been reported, serving a great purpose in understanding plant's response mechanisms to soil water deficit (Blum, 1996; Tardieu, 1996; Lawlor, 2002; Yordanov et al., 2000; Neumann, 2008; Ghannoum, 2009; Anjum et al., 2011; Pinheiro and Chaves, 2011). However, majority of these studies focused on qualitative impacts of soil water deficit with certain intensities on crop growth, based on experiments with very limited amounts of soil water levels.

In fact, only when soil water below a critical point that would exert significant impacts on crops (Blum, 1996; Sadras and Milroy, 1996; Ray et al., 2002; Streck, 2004; Novák, 2009; Gholipoor et al., 2012; Ramadas and Govindaraju, 2015; Esmaeilzade-Moridani et al., 2015). Any plant constituent and physiological process can be altered sequentially if soil water deficit is severe enough and lasts long enough, but they probably respond to different critical soil water status, namely, they have different sensitivities to soil water deficit (Hsiao, 1973; Hsiao et al., 1976; Andersen et al., 2002; Wu et al., 2011b). The sequence of changes in crop responding to soil water deficit and related critical thresholds are essential for identifying the extent of crop damage and improving drought prevention and resistance capabilities, which have been seldom drawn attention yet (Andersen et al., 2002). Hsiao et al. (1976) had reviewed extensive studies and evolved the sequence of changes of plant physiology and metabolism occurred in minutes or hours responding to water stress. Some studies attempted to identify critical soil water status of plant physiological and growth traits, but they were generally confined to certain aspects of plant growth, such as leaf expansion and leaf transpiration, lacking a comprehensive comparison among various levels of growth characteristics that reflect the plant growth status in response to water stress (Nable et al., 1999; Ray et al., 2002; Casadebaig et al., 2008; Heinemann et al., 2011).

The critical soil water thresholds were usually obtained either by direct observation of the critical points when the plant characteristics varied significantly or by calculating the stagnation points of the regression models between crop growth characteristics and their soil water status (Sadras and Milroy, 1996; Xu et al., 2010). Typical regression models included logistic regression model (Soltani et al., 2000; Toms and Villard, 2015), negative exponential regression model (Sadras and Milroy, 1996), quadratic polynomial model (Xu et al., 2010), plateau regression model (Nable et al., 1999; Wang et al., 2008; Yan et al., 2010; Wu et al., 2011a; Meir et al., 2015), and linear spline model (Soltani et al., 2000). However, the observed samples were usually quite limited due to the restriction of simulation experiments in the amounts and ranges of soil water gradients, which may not include the critical thresholds or be unable to establish a regression model well enough to accurately identify the critical thresholds.
Therefore, investigations on quantitative responses of various crop growth characteristics to a wide range of soil water conditions were of great necessity in order to accurately identify the sequence of changes in plant responding to soil water deficit and related critical soil water status, which would contribute to indicate the occurrence and development of drought and serve to more timely drought monitoring (Thompson et al., 2007).

Maize (Zea Mays L.) is the leading crop worldwide and pivotal to current and future global food security (Anjum et al., 2016). Usually, maize predominates in hot, arid regions which are prone to frequent drought and would likely be exacerbated by global climate change (Ghannoum, 2009). In this study, a 2-years' maize field experiment responding to soil water deficit were conducted, the aims were to (1) reveal the sequence of changes in maize responding to soil water deficit, and (2) identify critical soil water thresholds related to the sequence of changes in maize.

\section{MATERIALS AND METHODS}

\section{Site Descriptions}

The research site was at Gucheng Agrometeorological Experimental Station of China Meteorological Administration. It was located in Dingxing County, Baoding City, Hebei Province, China $\left(39^{\circ} 08^{\prime} \mathrm{N}, 115^{\circ} 40^{\prime} \mathrm{E}\right)$, belonging to the maize planting zone across wide Northern China. The station was equipped with an auto-rain-shelter, which covered an area of $750 \mathrm{~m}^{2}$ and was divided into 42 trial plots, each was $2 \mathrm{~m}$-wide $\times 4 \mathrm{~m}$-long and was isolated by $3 \mathrm{~m}$-deep concrete walls to prevent soil water exchange horizontally. The site has a typical cinnamon soil, containing $13.67 \mathrm{~g} \mathrm{~kg}^{-1}$ organic $\mathrm{C}, 0.87 \mathrm{~g} \mathrm{~kg}^{-1}$ total $\mathrm{N}, 25.76 \mathrm{mg}$ $\mathrm{kg}^{-1}$ available $\mathrm{P}$, and $118.55 \mathrm{mg} \mathrm{kg}^{-1}$ available $\mathrm{K}$. The soil bulk density is $1.37 \mathrm{~g} \mathrm{~cm}^{-3}$, and $\mathrm{pH}$ is 8.1 . The average field capacity and wilting point is 0.23 and $0.07 \mathrm{~g} \mathrm{~g}^{-1}$, respectively (Fang et al., 2013).

\section{Experimental Design}

A 2-years' maize field experiment responding to six initial soil water statuses was conducted in 2013 and 2014. Zhengdan 958, the most popular maize genotype in China was used in both years' experiments. In 2013, the maize was sown on 27 June with a $50 \mathrm{~cm}$ line spacing and a $30 \mathrm{~cm}$ row spacing, giving a plant density of 6.5 plants $\mathrm{m}^{-2}$. In 2014, the maize was sown on 24 June with a $50 \mathrm{~cm}$ line spacing and a $25 \mathrm{~cm}$ row spacing, giving a plant density of 8.0 plants $\mathrm{m}^{-2}$. Diammonium Phosphate fertilizer was applied at $300 \mathrm{~kg} \mathrm{ha}^{-1}$ before sowing each year, equal to the fertilization level of local field. All other agronomic managements were identical to the local field in both years.

A completely randomized block design with three replicate plots was applied in both years. Irrigation was performed every other day to ensure the relative soil moisture of 0-50 $\mathrm{cm}$ depth of each trial plot is above $65 \%$, maintaining normal growth of maize plants before they expanded the 7th leaf (July 24th, 2013) and the 3rd leaf (July 2nd, 2014), respectively (Guo et al., 2001; Xiao et al., 2011). Then, six different irrigations were performed. In 2013, the irrigation amounts (named 1st-6th treatments) were 100, 80, 60, 40,25 , and $15 \mathrm{~mm}$, respectively, equivalent to $125,100,75,50,30$, 
and $20 \%$ of the local average precipitation in late July $(80 \mathrm{~mm})$, respectively. In 2014, the irrigation amounts (named 1st-6th treatments) were $150,120,90,60,30$, and $10 \mathrm{~mm}$, respectively, equivalent to $100,80,60,40,20$, and $7 \%$ of the local average precipitation in July $(150 \mathrm{~mm})$, respectively. No extra irrigation was performed thereafter. Precipitation was blocked completely by the auto-rain-shelter during the entire growth period.

\section{Measurements}

We made one observation in the seedling stage on July 9th, 2014, and two observations in the jointing stage on July 31st, 2013, and August 8th, 2013, respectively. Eleven indicators involving plant water status, leaf gas exchange, morphology and biomass of maize were measured as candidates to investigate their responses to soil water deficit. They are moisture content of the stem and the leaf (LMC and SMC), net photosynthetic rate $(\mathrm{Pn})$, transpiration rate ( $\mathrm{Tr}$ ), stomatal conductance (Gs), leaf area (LA), root-shoot ratio (R/S), dry biomass of the leaf, the stem, and the root (LDB, SDB, and $\mathrm{RDB})$, and total dry biomass of the plant (TB).

\section{Leaf Gas Exchange}

Measurements on leaf gas exchange were performed with a Li6400 portable photosynthesis system equipped with a standard leaf chamber (LI-COR, Lincoln, NE, United States). The net $\mathrm{Pn}, \mathrm{Tr}$, and Gs were measured on the youngest fully expanded leaf under natural light between 9:00 am and 11:00 am in clear weather.

\section{Leaf Area (LA)}

The length $\left(L_{\mathrm{i}}\right)$ and width (the widest part of the leaf, $\left.D_{\mathrm{i}}\right)$ of every fully expanded leaf on the sample plants were measured. The length of inadequately expanded leaf was measured based on its exposed part from the last leaf, and its width was estimated based on its original shape without being spread out. LA $\left(\mathrm{m}^{2}\right)$ of individual maize plant was obtained by Eqn. (1):

$$
L A=\sum_{i=1}^{n} L_{i} \times D_{i} \times k
$$

Where $k(=0.75)$ is the shape factor (Francis et al., 1969).

\section{Biomass and Plant Water Status}

The fresh mass of leaf and stem was weighed, while the root was rinsed. They were separately put into kraft bags and dried in an oven at $80^{\circ} \mathrm{C}$ for more than $24 \mathrm{~h}$ until their weights were constant. Then, biomass of leaf, stem, and root was weighed, respectively. Stem moisture content (SMC), leaf moisture content (LMC), and root/shoot ratio $(\mathrm{R} / \mathrm{S})$ were calculated according to the following formulas (Peuke et al., 2002):

$$
\begin{aligned}
& \mathrm{SMC}=(\mathrm{SFB}-\mathrm{SB}) / \mathrm{SFB} \times 100 \% \\
& \mathrm{LMC}=(\mathrm{LFB}-\mathrm{LB}) / \mathrm{LFB} \times 100 \% \\
& \mathrm{R} / \mathrm{S}=\mathrm{RB} /(\mathrm{LB}+\mathrm{SB})
\end{aligned}
$$

Where SFB, SB, LFB, LB, and RB were stem fresh biomass, stem dry biomass, leaf fresh mass, leaf dry biomass, and root dry biomass, respectively.

\section{Soil Water Content}

Soil water content was measured by oven-drying method. One sampling point was randomly selected between two rows of maize in a trial plot and thus three samples obtained from each treatment in total. Soil samples of every $10 \mathrm{~cm}$ were collected from each sampling point. The total depth was up to $50 \mathrm{~cm}$ in 2013, while it was $90 \mathrm{~cm}$ in 2014 . The samples were weighed both before and after they were dried up in an oven at $105^{\circ} \mathrm{C}$. The relative soil moisture of $0-30 \mathrm{~cm}$ depth (RSM) was used here to describe soil water status (Eqn. 2), because it was most closely related to maize growth characteristics among all these measured depths (Supplementary Tables S1-S3).

$$
R S M=\frac{\sum_{i=1}^{3}\left(F S_{i}-D S_{i}\right) / \sum_{i=1}^{3} D S_{i}}{F C} \times 100 \%
$$

Where FS and DS were fresh and dry weights of soil samples from certain layers; $I$ was the number of soil layer $(i=1,2,3$ refers to soil layer $0-10,11-20$, and $21-30 \mathrm{~cm}$, respectively); $F C$ was the field capacity $\left(=0.23 \mathrm{~g} \mathrm{~g}^{-1}\right)$.

\section{Meteorological Data}

Meteorological data including temperature, relative humidity, wind speed, and total radiation at $1 \mathrm{~min}$ interval was obtained from the automatic weather station of Gucheng Agrometeorological Experimental Station. Vapor pressure deficit (VPD) was calculated by temperature and relative humidity.

\section{Tipping Points of Maize Growth and Related Critical RSM Thresholds}

The tipping point of plant growth characteristic is the very point when values of the characteristic start to deviate significantly from those with sufficient water supply, resulting from a decline in soil water content below a critical level (Thompson et al., 2007; Czajkowski et al., 2009). Here, the method named as oneside upper and lower tolerance limits for normal population was newly adopted to identify the tipping point of each growth characteristic.

Tolerance limit refers to either of two quantities that specify the endpoints of a tolerance interval. A tolerance interval is an estimated interval within which at least a certain proportion $P$ of the population falls at a given level of confidence $\gamma$ (ISO 16269-6, 2005; Krishnamoorthy and Mathew, 2009; Young, 2014). Their rigorous statistical definitions could be found in Young (2014). ISO 16269-6 (2005) provides computational formulas of tolerance intervals and limits for different distribution populations. Given the sampling methods of the field experiment, formulas of one-side upper and lower tolerance limits for normal population with unknown variance and unknown mean were used here (Eqn. 3 and 4).

$$
\begin{aligned}
& U(X)=\bar{X}+k \times S \\
& L(X)=\bar{X}-k \times S
\end{aligned}
$$

In the above, $U(X)$ and $L(X)$ are one-side upper and lower tolerance limits for normal population, respectively; $\bar{X}$ is the 
sample mean and $S$ is the sample variance; $k$ is the tolerance factor, varying with the sample size $n$, the confidence level $P$, and the $\gamma$ percentile of the population included, which could refer to ISO 16269-6 (2005) or be calculated directly (Krishnamoorthy and Mathew, 2009).

To be specific, according to the results of Duncan multiple test, the growth characteristics from experimental treatments which had received larger amounts of irrigation while had no significant differences were thought to be still free of soil water deficit. Its tipping point was obtained by calculating the tolerance limit of the observed samples from these treatments. In terms of a growth characteristic which decreases as soil moisture drops below a certain level, its tipping point could be found by calculating the lower tolerance limit of these observed samples. It means that the characteristic would be unlikely lower than this tolerance lower limit when soil water is sufficient, while values of this characteristic would be probably lower than this limit once it was confronted with soil water stress. Accordingly, the tipping points of growth characteristics whose values would increase once confronted with water stress could be found by calculating the upper tolerance limits of observed samples that free of soil water deficit.

Since the formulas above could be used only when the samples normally distributed, we should first check the normality of the samples.

The tipping points of different growth characteristics were further quantified by their values of critical RSM thresholds, which were calculated in terms of the tipping points and the quadratic polynomial regression models between each growth characteristic and RSM (Eqn. 5).

$$
X=a \times R S M^{2}+b \times R S M+c
$$

Where $X$ is the observed values of a maize growth characteristic; RSM (\%) is the relative soil moisture of $0-30 \mathrm{~cm}$ depth; $a, b$, and $c$ are the fitting coefficients of the regression model.

\section{Statistical Analysis}

One-way Multivariate Analysis of Variance (One-way MANOVA) was performed on RSM and each growth characteristic to assess their differences among treatments. Their means of each treatment were then compared by Duncan multiple test at 0.05 significance level. Factor analysis was used to extract a common factor from LMC and SMC to represent maize water status, and a common factor from net Pn, Gs, and $\operatorname{Tr}$ to represent leaf gas exchange, which would be subjected to exploratory path analysis to figure out how maize growth characteristics respond to soil water. Normality of the observed samples that would be subjected to the tolerant limits calculation was examined with Shapiro-Wilk method (Razali and Wah, 2011). All statistical analyses were performed by SPSS 17.0 software (SPSS Inc., Chicago, IL, United States), except that exploratory path analysis was performed by IBM SPSS AMOS 21.0 (SPSS Inc., Chicago, IL, United States). Figures were plotted by Origin 8.5 (OriginLab, United States). The critical RSM of each sensitive growth characteristic was calculated by Matlab software (Mathworks Matlab R2010b, United States). The data were shown as the mean \pm standard deviation (mean $\pm \mathrm{SD})$.

\section{RESULTS}

\section{Changes in Maize Responding to Soil Water Deficit Changes in Maize Responding to Soil Water Deficit in Seedling Stage}

In 2014, the first observation was conducted on 9 July, i.e., 7 days after irrigation controls. Maize plants of six irrigation treatments were all in seedling stage. RSM was significantly different among treatments (Tables 1, 2). SMC of the 3rd to 6 th treatments were significantly lower than those of the 1st and 2nd treatments; LMC of the 5th and 6th treatments were significantly lower than those of the 1 st-4th treatments; net

TABLE 1 | Significant levels of differences among treatments of RSM and maize growth characteristics.

\begin{tabular}{|c|c|c|c|c|}
\hline \multirow[t]{2}{*}{ Indicators } & \multirow[t]{2}{*}{ Units } & \multirow{2}{*}{$\begin{array}{c}\text { July 09, } 2014 \\
P\end{array}$} & \multirow{2}{*}{$\begin{array}{c}\text { July } 31,2013 \\
P\end{array}$} & \multirow{2}{*}{ August 08, 2013} \\
\hline & & & & \\
\hline RSM & $\%$ & $* * *$ & $* *$ & $* *$ \\
\hline Leaf moisture content & $\%$ & $* * *$ & $* *$ & $*$ \\
\hline Stem moisture content & $\%$ & $* * *$ & $* *$ & $* *$ \\
\hline Root-shoot ratio & - & 0.960 & 0.411 & 0.616 \\
\hline Leaf area & $\mathrm{cm}^{2}$ plant $^{-1}$ & $*$ & 0.458 & ** \\
\hline Leaf dry mass & g plant $^{-1}$ & 0.639 & 0.584 & 0.112 \\
\hline Stem dry mass & $\mathrm{g} \mathrm{plant}^{-1}$ & 0.599 & 0.664 & 0.153 \\
\hline Root dry mass & $\mathrm{g} \mathrm{plant}^{-1}$ & 0.978 & 0.122 & 0.318 \\
\hline Total dry mass & g plant $^{-1}$ & 0.961 & 0.573 & 0.127 \\
\hline Net photosynthetic rate & $\mu \mathrm{mol} \mathrm{CO} 2 \mathrm{~m}^{-2} \mathrm{~s}^{-1}$ & $* * *$ & 0.348 & $* * *$ \\
\hline Stomatal conductance & $\mathrm{mol} \mathrm{H}_{2} \mathrm{O} \mathrm{m}^{-2} \mathrm{~s}^{-1}$ & $* * *$ & 0.134 & $* *$ \\
\hline Transpiration rate & $\mathrm{mmol} \mathrm{H}{ }_{2} \mathrm{O} \mathrm{m}^{-2} \mathrm{~s}^{-1}$ & $* * *$ & 0.278 & $* *$ \\
\hline
\end{tabular}

*** $P<0.001,{ }^{* *} P<0.01,{ }^{*} P<0.05$. 
TABLE 2 | Duncan multiple test of RSM and sensitive growth characteristics of maize in seedling stage in 2014.

\begin{tabular}{|c|c|c|c|c|c|c|c|}
\hline Treatments & RSM & LA & LMC & SMC & Pn & $\mathrm{Tr}$ & Gs \\
\hline 1 & $96.5 \pm 1.0^{\mathrm{a}}$ & $121.2 \pm 24.6^{a}$ & $85.0 \pm 0.4^{a}$ & $90.7 \pm 0.3^{a}$ & $36.01 \pm 3.31^{a}$ & $10.21 \pm 1.31^{a}$ & $0.28 \pm 0.05^{a}$ \\
\hline 2 & $90.8 \pm 1.4^{b}$ & $122.0 \pm 16.1^{a}$ & $84.4 \pm 0.6^{a}$ & $90.2 \pm 0.4^{a b}$ & $32.46 \pm 1.42^{a b}$ & $9.18 \pm 0.42^{\mathrm{a}}$ & $0.24 \pm 0.02^{a b}$ \\
\hline 3 & $83.1 \pm 4.7^{c}$ & $107.9 \pm 3.2^{\mathrm{a}}$ & $84.1 \pm 0.6^{a}$ & $89.7 \pm 0.3^{b c}$ & $34.28 \pm 0.64^{a}$ & $9.13 \pm 0.11^{a}$ & $0.25 \pm 0.01^{a}$ \\
\hline 4 & $69.1 \pm 2.6^{d}$ & $114.1 \pm 2.4^{a}$ & $84.1 \pm 0.9^{a}$ & $89.1 \pm 0.4^{c}$ & $29.10 \pm 0.57^{b c}$ & $7.79 \pm 0.42^{b}$ & $0.20 \pm 0.02^{b c}$ \\
\hline 5 & $61.3 \pm 4.5^{\mathrm{e}}$ & $107.6 \pm 5.6^{a}$ & $81.8 \pm 0.4^{b}$ & $87.9 \pm 0.2^{\mathrm{d}}$ & $27.25 \pm 0.90^{c}$ & $7.09 \pm 0.36^{b}$ & $0.18 \pm 0.02^{\mathrm{C}}$ \\
\hline 6 & $45.3 \pm 1.1^{f}$ & $76.2 \pm 3.8^{b}$ & $77.9 \pm 1.8^{\mathrm{C}}$ & $86.0 \pm 0.4^{e}$ & $11.06 \pm 2.52^{d}$ & $2.93 \pm 0.51^{c}$ & $0.05 \pm 0.02^{d}$ \\
\hline
\end{tabular}

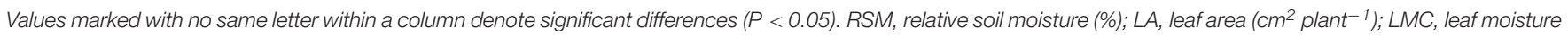

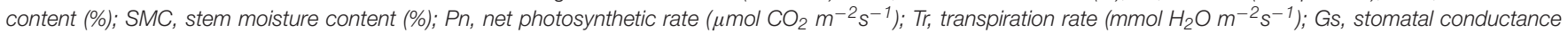
$\left(\mathrm{mol} \mathrm{H} \mathrm{H}_{2} \mathrm{~m}^{-2} \mathrm{~s}^{-1}\right)$.

Pn, Tr, and Gs of the 4th-6th treatments were significantly lower than those of the 1st-3rd treatments; leaf area of the 6th treatment was significantly lower than those of the 1st-5th treatments; biomass related characteristics still not appeared any significant difference under current soil water status (Tables 1, 2). Therefore, growth characteristics related to plant water status (SMC and LMC), leaf gas exchange (net Pn, $\mathrm{Tr}$, and Gs), and leaf area were more sensitive to soil water deficit among all these growth characteristics in the seedling stage.

\section{Changes in Maize Responding to Soil Water Deficit in Jointing Stage}

In 2013, the first observation was conducted on 31 July, 7 days after irrigation controls. Maize plants of six irrigation treatments were all in the jointing stage. RSM differed significantly among treatments (Tables 1, 3). Only stem and LMCs of the 6th treatment were significantly lower than those of the 1st-5th treatments (Tables 1, 3). On 8 August, i.e., the 14th day after irrigation controls, maize plants from the six treatments were still in the jointing stage. Differences in RSM among treatments were still significant (Tables 1, 3). LMC of the 5th and 6th treatments were much lower than that of the 1st treatment; SMC and Gs of the 4th-6th treatments were significantly lower than those of the 1st treatment; net $\mathrm{Pn}$ and $\mathrm{Tr}$ of the 5th and 6th treatments were significantly lower than those of the 1st-4th treatments; leaf area of the 5th and 6th treatments were significantly lower than those of the 1st and 2nd treatments; biomass-related characteristics were no apparent differences among treatments. Thus, growth characteristics related to plant water status (SMC and LMC), leaf gas exchange (net $\mathrm{Pn}, \mathrm{Tr}$, and Gs), and leaf area were more sensitive to soil water deficit among all these growth characteristics in jointing stage.

\section{Effects of Soil Water Deficit on Sequence of Changes in Maize}

The first common factors extracted from leaf and SMC based on the data of July 09, 2014, July 31, 2013, and August 08, 2013 account for 95.56, 85.64, and $82.57 \%$ of total variance, respectively. The first common factors extracted from net $\mathrm{Pn}$, Gs, and Tr based on the data of July 09, 2014, July 31, 2013, and August 08, 2013 account for 97.94, 86.92, and $94.84 \%$ of total variance, respectively. These common factors were subjected to exploratory path analysis as representatives of plant water status and leaf gas exchange. An initial exploratory path diagram (Supplementary Figure S2a) was established to evaluate both the direct and indirect effects of soil water on plant water status, leaf gas exchange, leaf area, and plant total biomass. The maximum likelihood method was adopted to calculate the regression weight of each path and the squared multiple correlation $\left(R^{2}\right)$ of each dependent variate. Insignificant paths were deleted in order to attain the criteria of the goodness-of-fit indices. The final path models were shown in Supplementary Figures S2b-d, respectively. The model fit summary (Supplementary Table S4) showed that the path analysis model generally had a reasonable fit for all the observation data (Arbuckle, 2010). Although the effective paths were not identical among path models based on different data, the results generally showed that RSM had the most significant total effects on plant water status, less on leaf gas exchange and leaf area, and the least on plant total biomass; besides, its effects on plant water status were direct, while its effects on leaf area, leaf gas exchange, and plant total biomass were major indirect. Plant water status generally had higher total effects than RSM on leaf gas exchange, leaf area, and plant total biomass, and its effects on leaf gas exchange and leaf area were direct, while it affected plant total biomass major indirectly via leaf area (Supplementary Tables S5, S6).

\section{Critical RSM Thresholds of Maize Responding to Soil Water Deficit}

Samples of all these sensitive growth characteristics distributed normally $(P>0.05)$ (Table 4$)$, and they all decreased due to soil water stress (Figures 1, 2). Thus, their tipping points were identified by calculating the lower tolerance limits of the observed samples at 0.95 lower confidence level and including $95 \%$ percentile of the population $(\gamma=0.95, P=95 \%$ ) (Eqn. 4; Tables 5, 6). The values of critical RSM were further calculated. The critical RSM threshold was about $72 \%$ for SMC, about $65 \%$ for LMC, about $62,60,58$, and $46 \%$ for $\mathrm{Tr}$, net $\mathrm{Pn}$, Gs, and leaf area, respectively, in seedling stage (Figure 1 and Table 5). In jointing stage, the critical RSM was about $64 \%$ for both stem and LMC, about 53, 51, 48, and 46\% for net $\mathrm{Pn}, \mathrm{Tr}, \mathrm{Gs}$, and leaf area, respectively (Figure 2 and Table 6). 


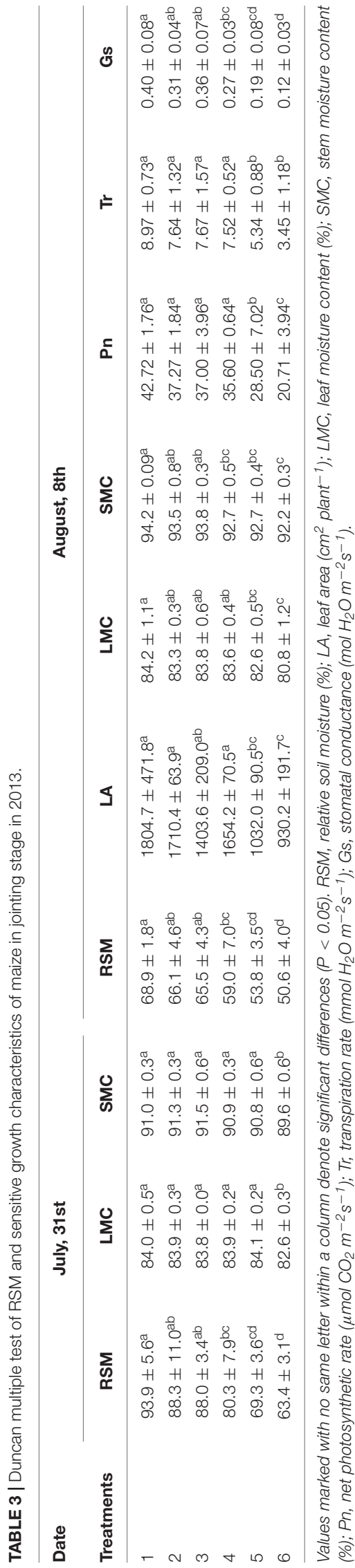

TABLE 4 | Shapiro-Wilk normal test for stress-free samples of maize growth characteristics.

\begin{tabular}{lccccc}
\hline $\begin{array}{l}\text { Sensitive growth } \\
\text { characteristics }\end{array}$ & \multicolumn{2}{c}{ Seedling stage (2014) } & & \multicolumn{2}{c}{ Jointing stage (2013) } \\
\cline { 2 - 3 } \cline { 5 - 6 } & Sample size & $\boldsymbol{P}$ & & Sample size & $\boldsymbol{P}$ \\
\hline SMC & 12 & 0.451 & & 15 & 0.696 \\
LMC & 22 & 0.923 & & 12 & 0.727 \\
Tr & 18 & 0.321 & & 12 & 0.982 \\
Pn & 18 & 0.356 & & 12 & 0.440 \\
Gs & 18 & 0.152 & & 12 & 0.798 \\
LA & 24 & 0.086 & 12 & 0.320 \\
\hline
\end{tabular}

SMC, stem moisture content (\%); LMC, leaf moisture content (\%); Pn, net photosynthetic rate $\left(\mu \mathrm{mol} \mathrm{CO} \mathrm{CO}^{-2} \mathrm{~s}^{-1}\right)$; Gs, stomatal conductance $\left(\mathrm{mol} \mathrm{H}_{2} \mathrm{O}\right.$

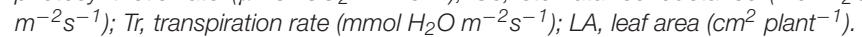

\section{Comparison on Meteorological Conditions}

The three performed observation days were identically clear days, and their daily dynamics of temperature, total radiation, wind speed were quite close, except that VPD of July 9th, 2014 was relatively higher than that of July 31st, 2013 and August 8th, 2013 (Supplementary Figure S1).

\section{DISCUSSION}

\section{Critical Soil Water Thresholds of Maize}

A threshold response of plant growth to soil or plant water status had been observed, that is, plant growth or physiological traits would remain almost constant until the water status was lower than a critical point (Blum, 1996; Sadras and Milroy, 1996; Ray et al., 2002; Novák, 2009; Gholipoor et al., 2012). In this study, maize growth characteristics appeared no significant difference among treatments with relatively higher soil moisture despite their soil water status were apparently different, however, they diverted significantly only in treatment(s) with lower soil moisture which was (were) below a certain level (Tables 1-3), implying their threshold responses to soil water status. Besides, the treatment differences were not identical among maize growth characteristics (Tables 2, 3), suggesting that they may have diverse critical soil moisture thresholds, namely, different sensitivities to soil water deficit. In both stages, growth characteristics related to plant water status (stem and LMC), leaf gas exchange (net Pn, Tr, and Gs), and leaf area varied at relatively higher soil moisture and thus were more sensitive to soil water deficit, while biomass-related characteristics appeared no significant difference under such wide soil water status (Tables 2, 3).

The results showed that the critical soil moisture thresholds were not identical either among growth characteristics or between stages (Tables 5, 6). In general, the critical soil moisture thresholds of maize growth characteristics in the seedling stage were higher than that in the jointing stage except that the critical soil moisture thresholds of leaf area were almost identical in both stages. The possible reason was that, in the seedling stage, 
A

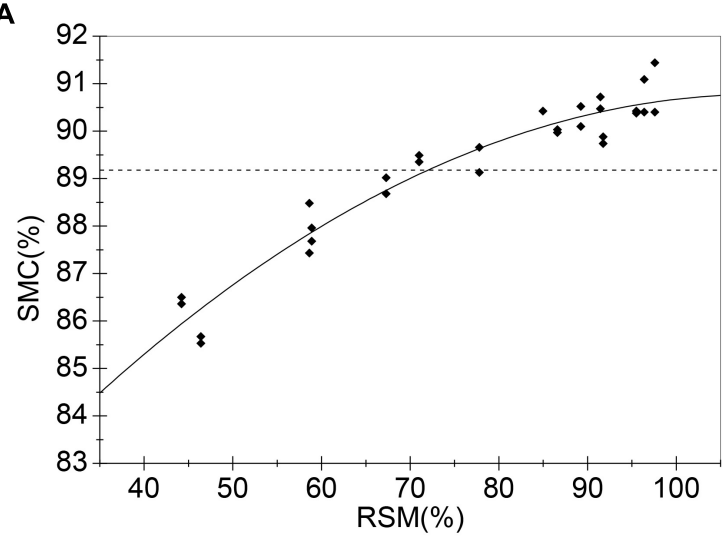

C

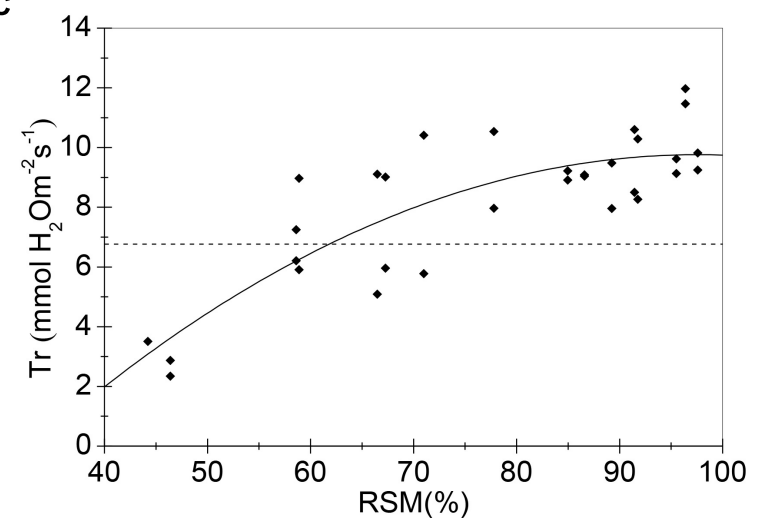

E

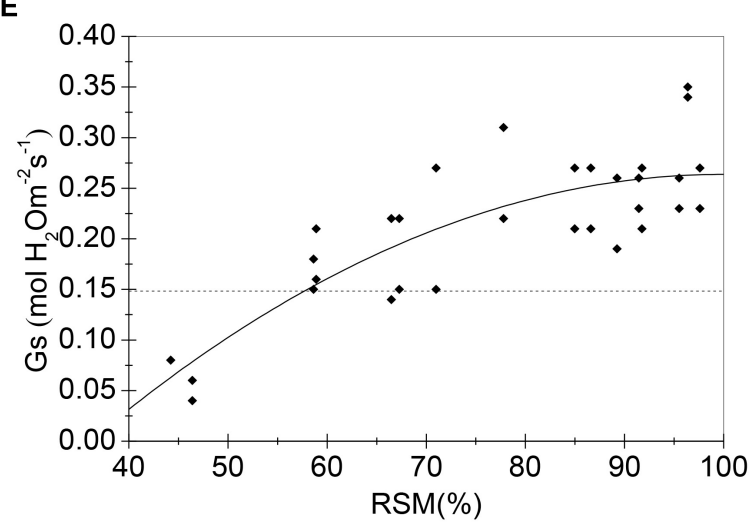

B

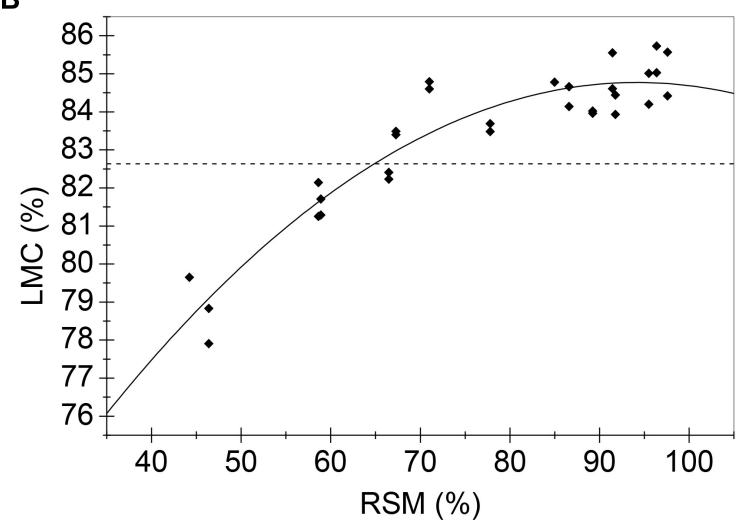

D

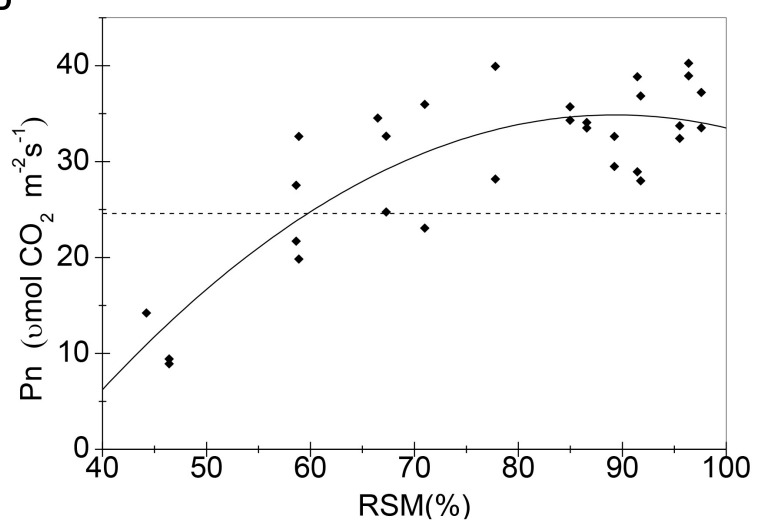

$\mathbf{F}$

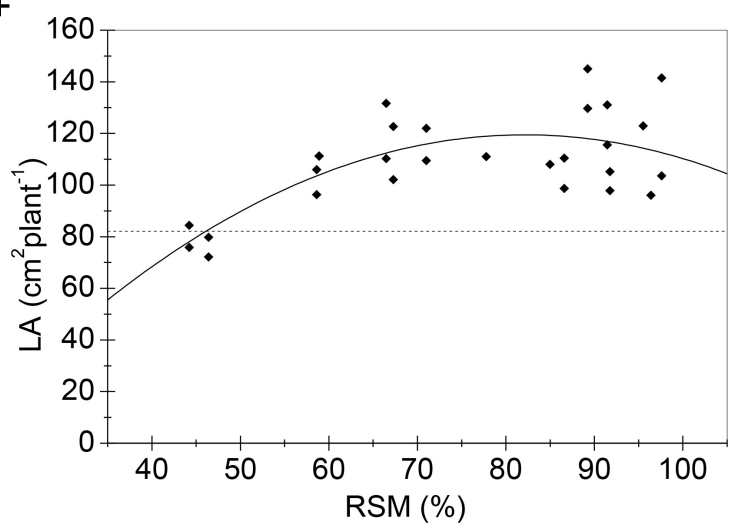

FIGURE 1 | Regression models (solid lines) of RSM and sensitive growth characteristics of maize in the seedling stage in 2014. (A) Stem moisture content (\%); (B) leaf moisture content (\%); (C) transpiration rate $\left(\mathrm{mmol} \mathrm{H}_{2} \mathrm{O} \mathrm{m}^{-2} \mathrm{~s}^{-1}\right)$; (D) net photosynthetic rate $\left(\mu \mathrm{mol} \mathrm{CO}_{2} \mathrm{~m}^{-2} \mathrm{~s}^{-1}\right)$; (E) stomatal conductance (mol $\mathrm{H}_{2} \mathrm{O}$ $\left.\mathrm{m}^{-2} \mathrm{~s}^{-1}\right)$; (F) leaf area $\left(\mathrm{cm}^{2}\right.$ plant $\left.{ }^{-1}\right)$. Closed squares refer to observed values; dashed lines refer to the tipping point of the growth characteristic.

compared to the jointing stage, the leaf water potential was higher (Sengupta and Majumder, 2014), the root was shallower, and leaves were smaller, which would result in weaker transpiration and poorer capability of soil water absorption (Kang and Liu, 1993). Thus, more abundant soil moisture was required to maintain high soil water potential to reduce the resistance of water absorption and to ensure water supply in the seedling stage (Ishida et al., 1992; Ying et al., 2015; Zhang et al., 2015).
Sadras and Milroy (1996) reviewed soil water thresholds (quantified by plant available water, PAW) of leaf expansion and leaf gas exchange among different species obtained under diverse experimental conditions. The average PAW threshold of leaf water potential was $0.61 \pm 0.09$, Gs was $0.37 \pm 0.05$, and leaf expansion was 0.56. Schmidt et al. (2001) found the tipping point of Gs of maize when PAW was 0.36. Ray et al. (2002) verified that the critical PAW of transpiration varied from 0.3 to 0.4 under different VPD. In our study, the PAW thresholds 
A

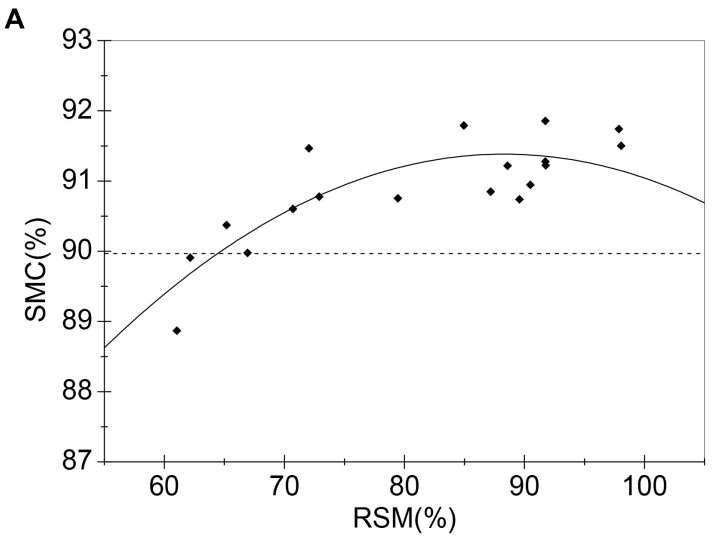

C

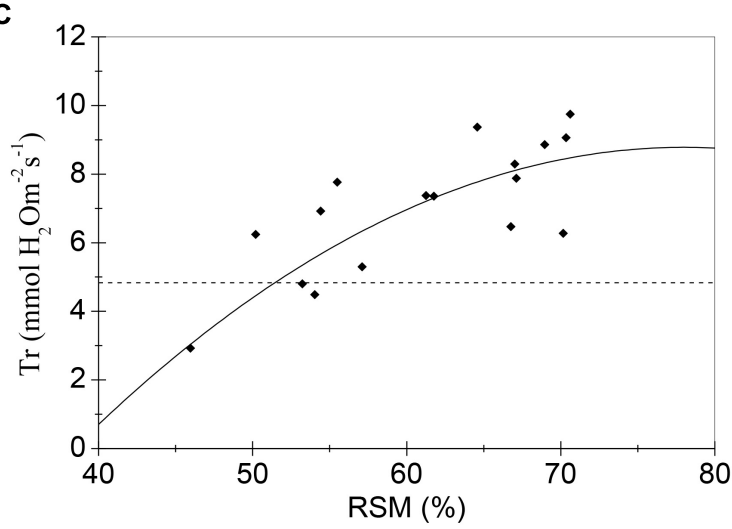

E

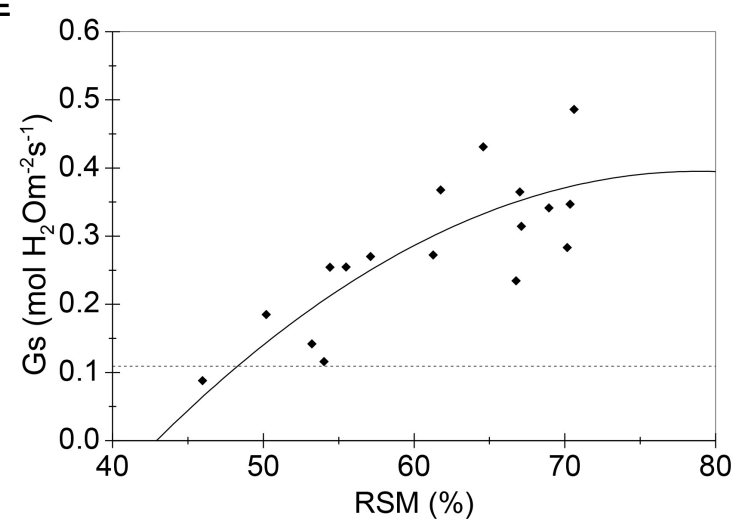

B

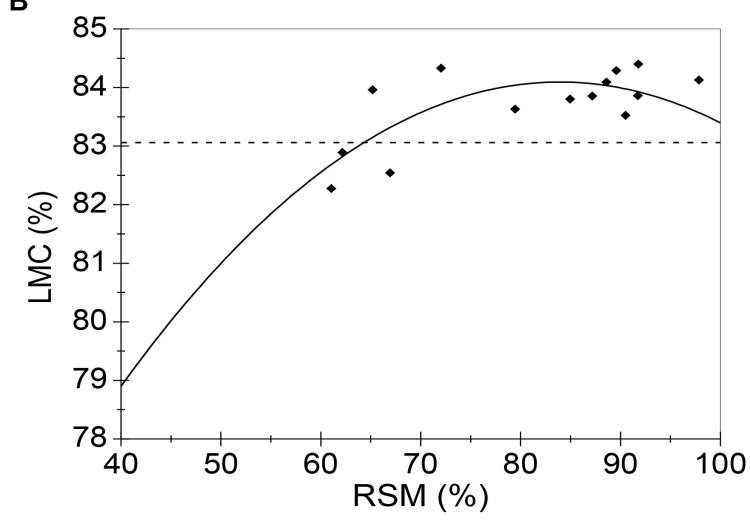

D

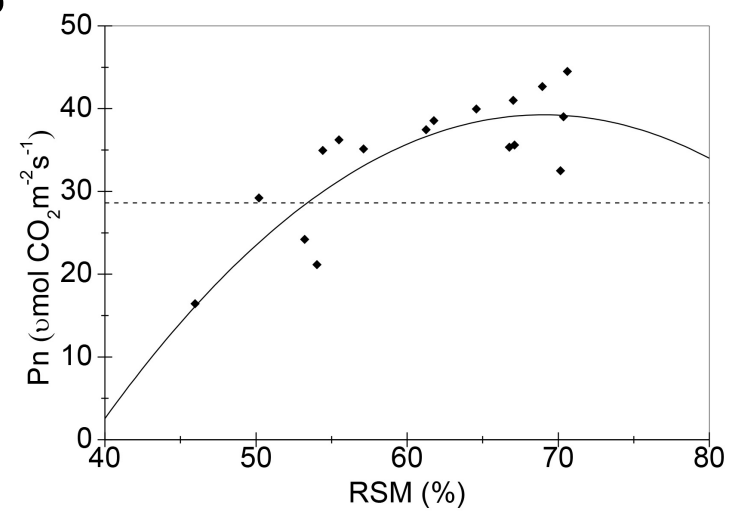

$\mathbf{F}$

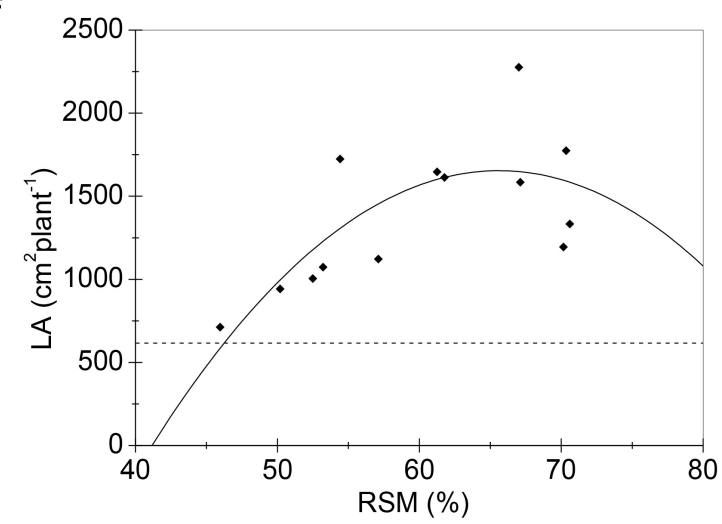

FIGURE 2 | Regression model (solid lines) of RSM and sensitive growth characteristics of maize in the jointing stage in 2013. (A) Stem moisture content (\%); (B) leaf moisture content (\%); (C) transpiration rate $\left(\mathrm{mmol} \mathrm{H}_{2} \mathrm{O} \mathrm{m}^{-2} \mathrm{~s}^{-1}\right)$; (D) net photosynthetic rate $\left(\mu \mathrm{mol} \mathrm{CO}_{2} \mathrm{~m}^{-2} \mathrm{~s}^{-1}\right) ;(\mathbf{E})$ stomatal conductance $\left(\mathrm{mol} \mathrm{H}_{2} \mathrm{O} \mathrm{m}^{-2} \mathrm{~s}^{-1}\right) ;(\mathbf{F})$ leaf area $\left(\mathrm{cm}^{2}\right.$ plant $\left.{ }^{-1}\right)$. Closed squares refer to observed values; dashed lines refer to the tipping point of the growth characteristic.

(converted from soil moisture) for SMC, LMC, Tr, net Pn, Gs, and leaf area were $0.58,0.48,0.43,0.40,0.37$, and 0.19 , respectively, in the seedling stage, while they were $0.46,0.46,0.27,0.30,0.22$, and 0.19 , respectively, in the jointing stage. The thresholds of $\operatorname{Tr}$ and Gs of this study were quite close to those from previous studies, in particular, those in the seedling stage almost coincided with the above results. However, these might merely coincidence, because these thresholds may vary dramatically among plant species, genotypes, phonology, soil property (i.e., soil texture and soil bulk density), root distribution, evaporative environment, growing conditions, and may also be influenced by regression models used and variations in determining the lower limit of PAW (Doorenbos and Kassam, 1980; Sadras and Milroy, 1996; Thompson et al., 2007; Casadebaig et al., 2008; Wu et al., 2011a; Schoppach and Sadok, 2012; Andrianasolo et al., 2016). For instance, PAW thresholds of maize could range from 0.27 to 0.85 for leaf expansion, and from 0.07 to 0.85 for leaf transpiration (Sadras and Milroy, 1996). 
TABLE 5 | The critical thresholds and critical RSM of sensitive growth characteristics of maize in the seedling stage in 2014.

\begin{tabular}{|c|c|c|c|c|c|c|c|}
\hline \multirow[t]{2}{*}{ Sensitive growth characteristics } & \multicolumn{3}{|c|}{ Parameters of regression models } & \multirow[t]{2}{*}{$R^{2}$} & \multirow[t]{2}{*}{ Critical thresholds } & \multicolumn{2}{|c|}{ Critical RSM } \\
\hline & a & $\mathbf{b}$ & c & & & Estimated values & $95 \%$ confidence interval \\
\hline SMC & -0.001 & 0.248 & 77.187 & 0.936 & 89.18 & $72 \%$ & {$[69 \%, 75 \%]$} \\
\hline LMC & -0.002 & 0.468 & 62.734 & 0.886 & 82.63 & $65 \%$ & {$[62 \%, 68 \%]$} \\
\hline $\operatorname{Tr}$ & -0.002 & 0.459 & -12.595 & 0.686 & 6.76 & $62 \%$ & {$[56 \%, 67 \%]$} \\
\hline $\mathrm{Pn}$ & -0.012 & 2.108 & -59.197 & 0.711 & 24.60 & $60 \%$ & {$[55 \%, 64 \%]$} \\
\hline Gs & $-6.461 E-5$ & 0.013 & -0.382 & 0.670 & 0.148 & $58 \%$ & {$[51 \%, 63 \%]$} \\
\hline$\llcorner A$ & -0.029 & 4.732 & -74.822 & 0.495 & 82.1 & $46 \%$ & [39\%, 52\%] \\
\hline
\end{tabular}

TABLE 6 | The critical thresholds and critical RSM of sensitive growth characteristics of maize in the jointing stage in 2013.

\begin{tabular}{|c|c|c|c|c|c|c|c|}
\hline \multirow{2}{*}{$\begin{array}{l}\text { Sensitive growth } \\
\text { characteristics }\end{array}$} & \multicolumn{3}{|c|}{ Parameters of regression models } & \multirow{2}{*}{$\begin{array}{c}R^{2} \text { of regression } \\
\text { models }\end{array}$} & \multirow{2}{*}{$\begin{array}{l}\text { Critical } \\
\text { thresholds }\end{array}$} & \multicolumn{2}{|c|}{ Critical RSM } \\
\hline & a & b & c & & & Estimated values & $95 \%$ confidence interval \\
\hline SMC & 0.002 & 0.439 & 71.986 & 0.661 & 89.96 & $64 \%$ & {$[60 \%, 68 \%]$} \\
\hline LMC & 0.002 & 0.452 & 65.133 & 0.544 & 83.06 & $64 \%$ & {$[59 \%, 68 \%]$} \\
\hline $\operatorname{Tr}$ & -0.006 & 0.871 & -25.219 & 0.607 & 4.83 & $51 \%$ & {$[44 \%, 55 \%]$} \\
\hline $\mathrm{Pn}$ & -0.044 & 6.014 & -168.289 & 0.702 & 28.60 & $53 \%$ & {$[50 \%, 56 \%]$} \\
\hline Gs & $-3.053 E-4$ & 0.048 & -1.505 & 0.719 & 0.109 & $48 \%$ & {$[40 \%, 52 \%]$} \\
\hline LA & -2.769 & 363.320 & -10264.4 & 0.530 & 616.9 & $46 \%$ & {$[41 \%, 50 \%]$} \\
\hline
\end{tabular}

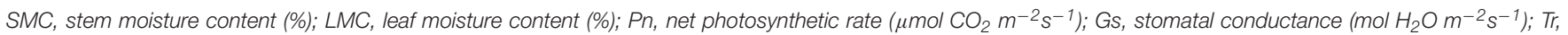
transpiration rate $\left(\mathrm{mmol} \mathrm{H}_{2} \mathrm{O} \mathrm{m} \mathrm{m}^{-2} \mathrm{~s}^{-1}\right) ; \mathrm{LA}$, leaf area $\left(\mathrm{cm}^{2}\right.$ plant $\left.{ }^{-1}\right)$.

\section{Sequence of Changes in Maize Responding to Soil Water Deficit}

The specific critical soil moisture thresholds of plant growth characteristics were not comparable among different studies, however, they may well reflect the sequence of changes in maize responding to soil water deficit (Sadras and Milroy, 1996). The critical RSM thresholds of maize showed the sequence of changes in maize as SMC $>$ LMC $>\operatorname{Tr}>\mathrm{Pn}>\mathrm{Gs}>\mathrm{LA}$ in seedling stage and $\mathrm{SMC} \geq \mathrm{LMC}>\mathrm{Pn}>\mathrm{Tr}>\mathrm{Gs}>\mathrm{LA}$ in jointing stage. Our study verified that plant water status was one of the earliest response to soil water deficit (Hsiao, 1973; Hsiao et al., 1976), followed by maize growth characteristics related to leaf water status, such as leaf water potential, leaf relative water content, and LMC which have long been used to indicate water stress (Hsiao, 1973; Hsiao et al., 1976; Ackerson et al., 1977; Kumar et al., 1994). Our study also showed that stem was more sensitive to water stress than leaf (Westgate and Boyer, 1985; McCutchan and Shackel, 1992; Shackel et al., 1997; Naor, 2000; Intrigliolo and Castel, 2006; Abrisqueta et al., 2015).

It has been found that stomata closed prior to decreases in $\mathrm{Tr}$ and Pn when confronted with water stress (Hsiao, 1973; Hsiao et al., 1976). However, in our study, the critical soil moisture of Gs in both stages were slightly lower than those of $\mathrm{Tr}$ and Pn. This was possibly because that Gs was quite sensitive to various factors more than soil water. For instance, stomatal interactions with environmental factors such as light and $\mathrm{CO}_{2}$ were complex and appeared to be mediated by several underlying processes
(Hsiao, 1973). Increasing VPD between the leaf-air interface would also result in stomata closure regardless of soil water status (Farooq et al., 2009). Besides, hormones such as abscisic acid (ABA) would regulate stomata aperture during the early stage of drought, whereas factors such as leaf water potential, nutrition situation, $\mathrm{pH}$ of sap flow and farnesyltransferase activity could affect stomata's sensitivity to ABA (Holbrook et al., 2002; Medrano et al., 2002). All these factors made Gs extremely variable, which resulted in greater variances within the samples that were subjected to tolerant limits calculation, yielding a broader tolerant limit and consequently lower critical RSM (Eqn. 4).

Expansion of mesophyll cells was thought to be even more sensitive to soil water deficit than the Gs and Pn (Hsiao, 1973; Hsiao et al., 1976; Fischer, 1980; Lambers et al., 2008). In contrast, our study found that leaf area responded at lower critical soil moisture than those of leaf gas exchange characteristics. In fact, they were not contradictory. Mesophyll cell expansion was a physiological process and thus responded instantly to water status, whereas leaf area was cumulative effects of soil water stress on mesophyll cell expansion as well as a result of adaptive growth of leaf under drought, which depended on not only expansion of all growing leaves, but also leaf number and the senescence of older leaves, consequently responding slower to drought (Reddy et al., 2003; Blum, 2011; Pinheiro and Chaves, 2011; Bodner et al., 2015).

Different sensitivities of maize growth characteristics to soil water deficit resulted from the way soil water affected them. 
The results of exploratory path analysis showed that soil water had the most significant total effects on plant water status, less on leaf gas exchange and leaf area. Besides, plant water status was directly affected by soil water, while leaf gas exchange and leaf area were more directly influenced by plant water status. Reductions in plant water status, especially leaf water status would give rise to a loss in turgor, which would on one hand reduce cell division and enlargement and consequently inhibit leaf expansion, on the other hand, lead to stomatal closure, consequently impeding $\mathrm{CO}_{2}$ influx and $\mathrm{H}_{2} \mathrm{O}$ outflux and thus leaf gas exchange (Hsiao, 1973; Blum, 2011; Pinheiro and Chaves, 2011; Sanders and Arndt, 2012). It implied that variations in leaf gas exchange and leaf area, to a greater extent, were secondary effects of soil water stress on plant water status, and thus they responded slower than plant water status to soil water deficit. The results of exploratory path analysis also showed that plant total biomass was directly influenced by leaf area, whereas soil moisture had no significantly direct effect on total biomass, nor had leaf water status, nor had leaf gas exchange. Plant total biomass was an accumulation of plant growth at various levels over a certain period, while soil moisture, plant water status, and leaf gas exchange were all instantaneous characteristics that only indicated water stress of the very time they were observed, so their effects could not be instantly detected from plant biomass. That's why all these three characteristics appeared no significant direct effect on plant total biomass. However, long term effects of soil water deficit on leaf expansion and leaf gas exchange both appeared as a reduction in leaf area at the whole plant level, which led to decreased transpiration as well as lower intercepted radiation, and ultimately decreased biomass production (Reddy et al., 2003; Blum, 2011; Pinheiro and Chaves, 2011; Sanders and Arndt, 2012). It implies that changes in plant biomass were integrated results of all these secondary or even tertiary effects of soil water deficit in a longer term.

\section{REFERENCES}

Abrisqueta, I., Conejero, W., Valdés-Vela, M., Vera, J., Ortuño, M. F., and RuizSánchez, M. C. (2015). Stem water potential estimation of drip-irrigated earlymaturing peach trees under Mediterranean conditions. Comput. Electron. Agric. 114, 7-13. doi: 10.1016/j.compag.2015.03.004

Ackerson, R., Krieg, D., Haring, C., and Chang, N. (1977). Effects of plant water status on stomatal activity, photosynthesis, and nitrate reductase activity of field grown cotton. Crop Sci. 17, 81-84. doi: 10.2135/cropscil977. 0011183X001700010023x

Alkaisi, M. M., Archontoulis, S. V., Kwawmensah, D., and Miguez, F. (2015). Tillage and crop rotation effects on corn agronomic response and economic return at seven Iowa locations. Agron. J. 2013, 399-412.

Andersen, M. N., Asch, F., Wu, Y., Jensen, C. R., Naested, H., Mogensen, V. O., et al. (2002). Soluble invertase expression is an early target of drought stress during the critical, abortion-sensitive phase of young ovary development in maize. Plant Physiol. 130, 591-604. doi: 10.1104/pp.005637

Andrianasolo, F. N., Casadebaig, P., Langlade, N., Debaeke, P., and Maury, P. (2016). Effects of plant growth stage and leaf aging on the response of transpiration and photosynthesis to water deficit in sunflower. Funct. Plant Biol. 43, 797-805. doi: 10.1071/FP15235

Anjum, S. A., Tanveer, M., Ashraf, U., Hussain, S., Shahzad, B., Khan, I., et al. (2016). Effect of progressive drought stress on growth, leaf gas exchange, and antioxidant production in two maize cultivars. Environ. Sci. Pollut. Res. Int. 23, 17132-17141. doi: 10.1007/s11356-016-6894-8

\section{AUTHOR CONTRIBUTIONS}

GZ, XM, and $\mathrm{QH}$ conceived and designed the research, analyzed the data, and wrote the manuscript. XM performed the experiments.

\section{FUNDING}

This research was jointly supported by National Natural Science Foundation of China (41330531 and 41501047), China Special Fund for Meteorological Research in the Public Interest (Major projects) (GYHY201506001-3), and the National Key Research and Development Program of China (2016YFD0300106).

\section{ACKNOWLEDGMENTS}

We thank Gucheng Agrometeorological Experimental Station of China Meteorological Administration for providing convenient experiment facilities. We thank Zhenzhu Xu from Institute of Botany, Chinese Academy of Sciences, for his critical suggestions. We also thank Feng Zhang, Yanling Jiang, Yaohui Shi, QiulingWang, Huailin Zhou, Minzheng Wang, YuheJi, Tao Liu, Bozhen Li, Li Zhang, Shaojun Liu, Jun Tang, Jian Song, and Shujie Zhang for their help during field work.

\section{SUPPLEMENTARY MATERIAL}

The Supplementary Material for this article can be found online at: https://www.frontiersin.org/articles/10.3389/fpls.2018.00511/ full\#supplementary-material

Anjum, S. A., Xie, X. Y., Wang, L. C., Saleem, M. F., Man, C., and Lei, W. (2011). Morphological, physiological and biochemical responses of plants to drought stress. Afr. J. Agr. Res. 6, 2026-2032.

Arbuckle, J. (2010). Amos Users' Guide Version 19.0. Chicago IL: SPSS, Inc.

Bajgain, R., Xiao, X., Basara, J., Wagle, P., Zhou, Y., Zhang, Y., et al. (2016). Assessing agricultural drought in summer over Oklahoma Mesonet sites using the water-related vegetation index from MODIS. Int. J. Biometeorol. 61, 1-14. doi: 10.1007/s00484-016-1218-8

Blum, A. (1996). Crop responses to drought and the interpretation of adaptation. Plant Growth Regul. 20, 135-148. doi: 10.1007/BF00024010

Blum, A. (ed.) (2011). "Plant water relations, plant stress and plant production," in Plant Breeding for Water-Limited Environments (New York, NY: Springer).

Bodner, G., Nakhforoosh, A., and Kaul, H. P. (2015). Management of crop water under drought: a review. Agron. Sustain. Dev. 35, 401-442. doi: 10.1007/s13593015-0283-4

Casadebaig, P., Debaeke, P., and Lecoeur, J. (2008). Thresholds for leaf expansion and transpiration response to soil water deficit in a range of sunflower genotypes. Eur. J. Agron. 28, 646-654. doi: 10.1016/j.eja.2008.02.001

Czajkowski, T., Ahrends, B., and Bolte, A. (2009). Critical limits of soil water availability (CL-SWA) for forest trees-an approach based on plant water status. Landbauforsch. Volkenrode 59, 87-94.

Denmead, O. T., and Shaw, R. H. (1962). Availability of soil water to plants as affected by soil moisture content and meteorological conditions. Agron. J. 54, 385-390. doi: 10.2134/agronj1962.000219620054000 $50005 \mathrm{x}$ 
Doorenbos, J., and Kassam, A. H. (1980). Yield response to water. Irrig. Agric. Dev. 33, 257-280. doi: 10.1016/B978-0-08-025675-7.50021-2

Esmaeilzade-Moridani, M., Kamkar, B., Galeshi, S., Ghaderi-Far, F., and Teixeira Da Silva, J. A. (2015). Leaf expansion and transpiration responses of millet species to soil water deficit. Pedosphere 25, 834-843. doi: 10.1016/S10020160(15)30064-3

Fang, S., Su, H., Liu, W., Tan, K., and Ren, S. (2013). Infrared warming reduced winter wheat yields and some physiological parameters, which were mitigated by irrigation and worsened by delayed sowing. PLoS One 8:e67518. doi: 10.1371/ journal.pone. 0067518

Farooq, M., Wahid, A., Kobayashi, N., Fujita, D., and Basra, S. (2009). Plant drought stress: effects, mechanisms and management. Agron. Sustain. Dev. 29, 185-212. doi: 10.1051/agro:2008021

Fischer, R. A. (1980). "Influence of water stress on crop yield in semiarid regions," in Adaptation of Plants to Water and High Temperature Stress, eds N. C. Turner and P. Kramer (New York, NY: Wiley), 323-340.

Francis, C., Rutger, J., and Palmer, A. (1969). A rapid method for plant leaf area estimation in maize (Zea mays L.). Crop Sci. 9, 537-539. doi: 10.2135/ cropsci1969.0011183X000900050005x

Ghannoum, O. (2009). C4 photosynthesis and water stress. Ann. Bot. 103, 635-644. doi: $10.1093 / \mathrm{aob} / \mathrm{mcn} 093$

Gholipoor, M., Sinclair, T. R., and Prasad, P. V. (2012). Genotypic variation within sorghum for transpiration response to drying soil. Plant Soil 357, 35-40. doi: 10.1007/s11104-012-1140-8

Guo, R., Lin, Z., Mo, X., and Yang, C. (2010). Responses of crop yield and water use efficiency to climate change in the north china plain. Agric. Water Manage. 97, 1185-1194. doi: 10.1016/j.agwat.2009.07.006

Guo, X. P., Kang, S. Z., and Suo, L. S. (2001). Effects of regulated deficit irrigation on root growth in Maize. Irrig. Drain. 20, 25-27.

Heinemann, A. B., Stone, L. F., and Fageria, N. K. (2011). Transpiration rate response to water deficit during vegetative and reproductive phases of upland rice cultivars. Sci. Agric. 68, 24-30. doi: 10.1590/S0103-901620110001 00004

Holbrook, N. M., Shashidhar, V., James, R. A., and Munns, R. (2002). Stomatal control in tomato with ABA-deficient roots. J. Exp. Bot. 53, 1503-1514.

Hsiao, T., Fereres, E., Acevedo, E., and Henderson, D. (1976). "Water stress and dynamics of growth and yield of crop plants," in Water and Plant Life: Problems and Modern Approaches, eds O. L. Lange, L. Kappen, and E. D. Schulze (Berlin: Springer-Verlag), 281-305.

Hsiao, T. C. (1973). Plant responses to water stress. Annu. Rev. Plant phys. 24, 519-570. doi: 10.1146/annurev.pp.24.060173.002511

Intrigliolo, D. S., and Castel, J. R. (2006). Performance of various water stress indicators for prediction of fruit size response to deficit irrigation in plum. Agric. Water Manage. 83, 173-180. doi: 10.1016/j.agwat.2005.12.005

Ishida, A., Yamamura, Y., and Hori, Y. (1992). Roles of leaf water potential and soil-to-leaf hydraulic conductance in water use by understorey woody plants. Ecol. Res. 7, 213-223. doi: 10.1007/BF02347090

ISO 16269-6 (2005). Statistical Interpretation of Data - Part 6: Determination of Statistical Tolerance Intervals. Geneva: ISO.

Kang, S., and Liu, X. (1993). Distribution of hydraulic resistance and water potential in soil-plant-atmosphere continuum during growing period of maize. Chin. J. Appl. Ecol. 4, 260-266.

Krishnamoorthy, K., and Mathew, T. (2009). Statistical Tolerance Regions: Theory, Applications, and Computation. Hoboken, NJ: Wiley. doi: 10.1002/ 9780470473900

Kumar, A., Singh, D. P., and Singh, P. (1994). Influence of water stress on photosynthesis, transpiration, water-use efficiency and yield of Brassica juncea L. Field Crop. Res. 37, 95-101. doi: 10.1016/0378-4290(94)90037-X

Lambers, H., Chapin, F. S. III, and Pons, T. L. (2008). Plant Water Relations. New York, NY: Springer, 163-223. doi: 10.1007/978-0-387-78341-3_5

Lawlor, D. W. (2002). Limitation to photosynthesis in water-stressed leaves: stomata vs. metabolism and the role of ATP. Ann. Bot. 89, 871-885. doi: $10.1093 / \mathrm{aob} / \mathrm{mcf1} 10$

McCutchan, H., and Shackel, K. A. (1992). Stem-water potential as a sensitive indicator of water stress in prune trees (Prunus domestica L.cv. French). J. Am. Soc. Hortic. Sci. 117, 607-611.

Medrano, H., Escalona, J. M., Bota, J., Gulías, J., and Flexas, J. (2002). Regulation of photosynthesis of C3 plants in response to progressive drought: stomatal conductance as a reference parameter. Ann. Bot. 89, 895-905. doi: 10.1093/aob/ mcf079

Meir, P., Wood, T. E., Galbraith, D. R., Brando, P. M., Da Costa, A. C., Rowland, L., et al. (2015). Threshold responses to soil moisture deficit by trees and soil in tropical rain forests: insights from field experiments. Bioscience 65, 882-892. doi: 10.1093/biosci/biv107

Meng, L., Ding, W., and Cai, Z. (2005). Long-term application of organic manure and nitrogen fertilizer on $\mathrm{n} 2 \mathrm{o}$ emissions, soil quality and crop production in a sandy loam soil. Soil Biol. Biochem. 37, 2037-2045. doi: 10.1016/j.soilbio.2005. 03.007

Nable, R. O., Robertson, M. J., and Berthelsen, S. (1999). Response of shoot growth and transpiration to soil drying in sugarcane. Plant Soil 207, 59-65. doi: 10.1023/A:1004469417374

Naor, A. (2000). Midday stem water potential as a plant water stress indicator for irrigation scheduling in fruit tresss. Acta Hortic. 537, 447-454. doi: 10.17660/ ActaHortic.2000.537.52

Neumann, P. M. (2008). Coping mechanisms for crop plants in drought-prone environments. Ann. Bot. 101, 901-907. doi: 10.1093/aob/men018

Novák, V. (2009). "Physiological drought - how to quantify it?" in Bioclimatology and Natural Hazards, eds K. Střelcová, C. Matyas, A. Kleidon, M. Lapin, F. Matejka, M. Blazenec, et al. (New York, NY: Springer), 89-95. doi: 10.1007/9781-4020-8876-6 7

Petrov, P., Petrova, A., Dimitrov, I., Tashev, T., Olsovska, K., Brestic, M., et al. (2017). Relationships between leaf morpho-anatomy, water status and cell membrane stability in leaves of wheat seedlings subjected to severe soil drought. J. Agrono. Crop Sci. 1-9. doi: 10.1111/jac.12255 [Epub ahead of print].

Peuke, A. D., Schraml, C., Hartung, W., and Rennenberg, H. (2002). Identification of drought-sensitive beech ecotypes by physiological parameters. New Phytol. 154, 373-387. doi: 10.1046/j.1469-8137.2002.00400.x

Pinheiro, C., and Chaves, M. M. (2011). Photosynthesis and drought: can we make metabolic connections from available data? J. Exp. Bot. 62, 869-882. doi: $10.1093 / \mathrm{jxb} / \mathrm{erq} 340$

Porporato, A., Laio, F., Ridolfi, L., and Rodriguez-Iturbe, I. (2001). Plants in water- controlled ecosystems: active role in hydrologic processes and response to water stress III. Vegetation water stress. Adv. Water Resour. 24, 725-744. doi: 10.1016/S0309-1708(01)00006-9

Ramadas, M., and Govindaraju, R. S. (2015). Probabilistic assessment of agricultural droughts using graphical models. J. Hydrol. 526, 151-163. doi: 10.1016/j.jhydrol.2014.09.026

Ray, J. D., Gesch, R. W., Sinclair, T. R., and Allen, L. H. (2002). The effect of vapor pressure deficit on maize transpiration response to a drying soil. Plant Soil 239, 113-121. doi: 10.1023/A:1014947422468

Razali, N. M., and Wah, Y. B. (2011). Power comparisons of Shapiro-Wilk, Kolmogorov-Smirnov, Lilliefors and Anderson-Darling tests. J. Statist. Model. Analyt. 2, 21-33.

Reddy, T. Y., Reddy, V. R., and Anbumozhi, V. (2003). Physiological responses of groundnut (Arachis hypogea L.) to drought stress and its amelioration: a critical review. Plant Growth Regul. 41, 75-88. doi: 10.1023/A:1027353430164

Sadras, V. O., and Milroy, S. P. (1996). Soil-water thresholds for the responses of leaf expansion and gas exchange: a review. Field Crop Res. 47, 253-266. doi: 10.1016/0378-4290(96)00014-7

Sanders, G. J., and Arndt, S. K. (2012). Plant Responses to Drought Stress. Berlin: Springer, 130.

Schmidt, J. J., Blankenship, E. E., and Lindquist, J. L. (2001). Corn and velvetleaf (Abutilon theophrasti) transpiration in response to drying soil. Weed Sci. 59, 50-54. doi: 10.1614/WS-D-10-00078.1

Schoppach, R., and Sadok, W. (2012). Differential sensitivities of transpiration to evaporative demand and soil water deficit among wheat elite cultivars indicate different strategies for drought tolerance. Environ. Exp. Bot. 84, 1-10. doi: 10.1016/j.envexpbot.2012.04.016

Sengupta, S., and Majumder, A. L. (2014). Physiological and genomic basis of mechanical-functional trade-off in plant vasculature. Front. Plant Sci. 5:224. doi: $10.3389 /$ fpls.2014.00224

Shackel, K. A., Ahmadi, H., Biasi, W., Buchner, R., Goldhamer, D., Gurusinghe, S., et al. (1997). plant water status as an index of irrigation need in deciduous fruit trees. Hortechnology 7, 23-29.

Soltani, A., Khooie, F., Ghassemi-Golezani, K., and Moghaddam, M. (2000). Thresholds for chickpea leaf expansion and transpiration response to soil 
water deficit. Field Crop Res. 68, 205-210. doi: 10.1016/S0378-4290(00) 00122-2

Streck, N. A. (2004). Do we know how plants sense a drying soil? Ciên. Rural Santa Maria 34, 581-584. doi: 10.1590/S0103-84782004000200039

Tardieu, F. (1996). "Drought perception by plants do cells of droughted plants experience water stress?," in Drought Tolerance in Higher Plants: Genetical, Physiological and Molecular Biological Analysis, ed. E. Belhassen (Dordrecht: Springer).

Testa, G., Reyneri, A., and Blandino, M. (2016). Maize grain yield enhancement through high plant density cultivation with different inter-row and intra-row spacings. Eur. J. Agron. 72, 28-37. doi: 10.1016/j.eja.2015.09.006

Thompson, R. B., Gallardo, M., Valdez, L. C., and Fernández, M. (2007). Using plant water status to define threshold values for irrigation management of vegetable crops using soil moisture sensors. Agric. Water Manage. 88, 147-158. doi: 10.1016/j.agwat.2006.10.007

Toms, J. D., and Villard, M. A. (2015). Threshold detection: matching statistical methodology to ecological questions and conservation planning objectives. Avian Conserv. Ecol. 10:2. doi: 10.5751/ACE-00715-100102

Wang, Z. Y., Li, F. M., Xiong, Y. C., and Xu, B. C. (2008). Soil-water threshold range of chemical signals and drought tolerance was mediated by ROS homeostasis in winter wheat during progressive soil drying. J. Plant Growth Regul. 27, 309-319. doi: 10.1007/s00344-008-9057-4

Westgate, M. E., and Boyer, J. S. (1985). Osmotic adjustment and the inhibition of leaf, root, stem and silk growth at low water potentials in maize. Planta 164, 540-549. doi: 10.1007/BF00395973

Wu, Y., Huang, M., and Warrington, D. N. (2011a). Growth and transpiration of maize and winter wheat in response to water deficits in pots and plots. Environ. Exp. Bot. 71, 65-71. doi: 10.1016/j.envexpbot.2010.10.015

Wu, Y., Huang, M., and Warrington, D. (2011b). Responses of different physiological indices for maize (Zea mays L.) to soil water availability. Pedosphere 21, 639-649. doi: 10.1016/S1002-0160(11) 60166-5

Xiao, J. F., Liu, Z. D., Liu, Z. G., and Nan, J. Q. (2011). Effects of drought at different growth stages and different water availabilities on growth and water consumption characteristics of summer Maize. J. Maize Sci. 19, 64.
Xu, B. C., Deng, X. P., Zhang, S. Q., and Shan, L. (2010). Biomass partition, leaf gas exchange and water relations of alfalfa and milkvetch seedlings in response to soil drying. Photosynthetica 48, 481-487. doi: 10.1007/s11099-0100064-x

Yan, M., Yamanaka, N., Yamamoto, F., and Du, S. (2010). Responses of leaf gas exchange, water relations, and water consumption in seedlings of four semiarid tree species to soil drying. Acta Physiol. Plant. 32, 183-189. doi: 10.1007/s11738009-0397-X

Ying, Y. Q., Song, L. L., Jacobs, D. F., Mei, L., Liu, P., Jin, S. H., et al. (2015). Physiological response to drought stress in Camptotheca acuminata seedlings from two provenances. Front. Plant Sci. 6:361. doi: 10.3389/fpls.2015. 00361

Yordanov, I., Velikova, V., and Tsonev, T. (2000). Plant responses to drought, acclimation, and stress tolerance. Photosynthetica 38, 171-186. doi: 10.1023/A: 1007201411474

Young, D. S. (2014). Computing tolerance intervals and regions using R. Handb. Stat. 32, 309-338. doi: 10.1016/B978-0-444-63431-3. 00008-5

Zhang, M., Jin, Z. Q., Zhao, J., Zhang, G., and Wu, F. (2015). Physiological and biochemical responses to drought stress in cultivated and Tibetan wild barley. Plant Growth Regul. 75, 567-574. doi: 10.1007/s10725-014-0022-x

Zivcak, M., Brestic, M., Olsovska, K., and Slamka, P. (2008). Performance index as a sensitive indicator of water stress in Triticum aestivum L. Plant Soil Environ. $119,133-139$

Conflict of Interest Statement: The authors declare that the research was conducted in the absence of any commercial or financial relationships that could be construed as a potential conflict of interest.

Copyright (c) $2018 \mathrm{Ma}, \mathrm{He}$ and Zhou. This is an open-access article distributed under the terms of the Creative Commons Attribution License (CC BY). The use, distribution or reproduction in other forums is permitted, provided the original author(s) and the copyright owner are credited and that the original publication in this journal is cited, in accordance with accepted academic practice. No use, distribution or reproduction is permitted which does not comply with these terms. 